\title{
The Evaluation of the Computer as an Assistant in Language Teaching and Learning
}

\author{
Rui Fu \\ Foreign Language Department, Shenyang University, Shenyang, Liaoning, China \\ 65429725@qq.com
}

\begin{abstract}
Computer is applied in so many ways to assist education nowadays. The foreign language teaching and learning is not an exception. This paper is about the description and evaluation of the computer-aided education in learning and teaching English as a foreign language. Three main ways of the adoption are described in details.
\end{abstract}

Keywords-evaluation; language; teaching; learning

\section{INTRODUCTION}

With the development of science and technology, computer becomes more and more popular in every aspect. With the help of computer and Internet, it is possible for someone to get connected with the whole world. As a result, it is easy to get more information from different cultures and particularly, by using English as a medium. This provides a new option for modern language teachers. They should not only know the language or how to use the computer but also know how to teach the language with the assistance of computers. Therefore, computer assisted language learning became a method rather than an aid since it "has increased phenomenally over the past decade" [1]. As defined by Davies [2] "Computer Assisted Language Learning (CALL) is often perceived, somewhat narrowly, as an approach to language teaching and learning in which the computer is used as an aid to the presentation, reinforcement and assessment of material to be learned, usually including a substantial interactive element". This is what the teachers should consider when using computers in their teaching situation. This paper is about the description and evaluation of how to use the computer as an assistant to teaching and learning English as an foreign language. There are various ways of using computers in language classroom, including the word processor, CD-ROMs and the Internet. The use of computers will be illustrated in reference to some certain teaching and learning contexts.

\section{THE WORD PROCESSOR}

The various applications of word processing for developing writing skills have been well documented as mentioned by Jarvis [3]. He distinguishes two ways of using the word processor in the EFL classroom "a text specified approach" with a given text and "a process approach", in which the text is student generated [4]. These two approaches clearly show the fact that the word processor improves both the writing skills and language. As Jarvis [5] states, "both frameworks are valid and relevant when discussing writing and word processing in the language classroom." Also, the students may have various reasons for using word processing, "such as its being a useful skill in itself, a modern way of writing, and a help in motivating them to improve their written English" [6]. Piper [7] also shows that word processors can make a positive contribution to the development of students' writing skills. Therefore, the use of word processors can constitute a stronger motivation for students in order to complete their tasks.

However, as Beatty [8] reminds, most word-processing programs and other applications are "designed for business environments where learning is less important". That means the word processor is not designed for teaching languages. Also, the grammar support is "sometimes of questionable worth". That proves the fact that to improve the learners' writing skills, teachers cannot rely on the word-processing program alone. On the other hand, the existence of multimedia solves this problem and provides the chances of practicing not only the skill of writing but also listening, speaking and reading. In addition, the multimedia offers the opportunity of integration of the four skills together.

\section{CD ROMS}

Multimedia is defined by Brett [9] as "the computerdelivered combination of a large range of communications elements - text, sound, graphics, pictures, photographs, animation and moving video". It shows a difference from other media used in the EFL classroom such as video, audiotapes, and poster visuals. As one of the multimedia materials, CD ROMs are a kind of software with both dedicated and authoring packages. The students can complete different activities independently, since CD-ROMs belong to the category of computer as tutor. The activities provide practice in learning English and promote learners' autonomy. However, due to technical reasons, once the software is in operation, it can hardly change. That means it can easily become out-of-date as time goes by. Therefore, teachers need to evaluate the CD-ROMs before using them. According to the criteria from St. Clair County Regional Office of Education (2000), a good CD ROM should have the following characteristics: Presents interesting tasks that require the skills and knowledge to complete them; provides a safe environment for failures and successes. Meets a wide range of student abilities and learning styles; directions easy to follow; is fun, interesting, challenging for students; authentic environment; higher order thinking skills; cooperative environment; possesses good sound and visuals; consistent with graded course of study, state/national standards, and assessments and teacher support. The best CD 
ROM is the one that suits the above characteristics the most. Comparatively, the Internet has the advantage of time and authenticity.

There are some programs in CD ROMs in the computer room to help teaching and learning English. However, since the students do not have the chance to use the programs alone. Without the supervision of the teacher, the learners are encouraged to buy some programs in the PC software market and use them at home. The teachers also have the responsibility to help them choose the better quality program according to the evaluation mentioned earlier. It is worth mentioning that, the language labs are replaced by multimedia classrooms and some special kinds of computers with specific CD ROMs are commonly used to help improve learners' listening comprehension. The activities in this program are gap fillings, multiple-choices, matching, sequencings, tables and charts, note-takings, etc. The learners can do everything by themselves in front of the computer and the teachers' role is to help with the instructions about how to use it correctly.

\section{THE INTERNET}

Nowadays, Internet is no more a strange word and world to most people. It contains an extremely bigger resource than any other media in the world. As Windeatt, Hardisty \& Eastment [10] notice, "The main distinguishing feature of the internet, which sets it apart from more traditional types of CALL, is that it is a medium of exploration." That means the Internet can broaden learners' outlook and enrich their knowledge at the same time. They could find out whatever materials they like without any restrictions but faster than any library. The Internet economizes everyone's time, money, and energy and provides more opportunity to learn English such as through the WWW, E-mail, MOOs, etc.

\section{A. $\quad$ The dedicated World Wide Web}

Comparing with CD ROM software, the advantage of the dedicated WWW designed for English learning is that most of the websites are free and updated. They are called dedicated because they are specifically made for learners of English [11] and they contain activities like, gap-filling, multiple-choice, matching, sequencing, etc. They can be used as supplementary materials after class for EFL students of different levels and for different purposes. The activities, tasks, exercises, and quizzes with the easy-followed instructions in it are fairly interesting and moderate, and they can encourage learners' autonomy. Moreover, some of them have tutorials with someone on the other side of the screen, which can be quite motivating. However, some of the websites with commercial aims might not be very reliable, because they focus on selling their products. Choosing which one is helpful for the learners is not easy to decide.

On the other hand, there are great selections of publications on the Internet, like The British Journal of Education Technology or System as mentioned by Jarvis [12], which help towards improving the teachers' teaching skills. To promote the learners' motivation, some dedicated world wide web can be provided before their holiday time, such as, http://www.eslcafe.com/ $\quad$ http://vlc.polyu.edu.hk/ http://a4esl.org etc. The students can improve their weaknesses accordingly by self-study.

\section{B. The authentic World Wide Web}

In his book, Teeler [13] shows several advantages of using the Internet as a source of teaching materials: scope, topicality, and personalization. Everything related to the course books could be found in it. It can be used as material storing space for both teachers and students. However, the storing is so complicated that it is easy to get lost. That means, even the teachers need to be trained before accessing it and the learners need more instructions on how to pick out the suitable resources they need. They have the advantage of authenticity and of the variety of subjects that can attract every student's interest. However, because there are too many links, the learners can easily get lost, so they may need training before accessing.

The email can make the distance between teachersstudents and students - students shorter and make the communication more convenient. The teachers can encourage their students to ask questions by using email. They can also choose different kinds of electronic cards, write some sample sentences, and send them on some special date like the western holidays or the students' birthday. The students will reply the grateful electronic cards in their own words. Likewise, the learners are encouraged to do the same thing to each other. Hence, the practical written skill is performed [14]. Nevertheless, in order to achieve theirs goals of training, teachers need more skills to develop the application of the Internet.

\section{Teachers' assistant}

Most teachers can benefit even more than their students because all the materials offered from the Internet are "quickly, cheaply and readily available from the comfort of our desk or homes" [15]. As mentioned by Carballo-Calero [16], "the teacher's presence will be more necessary when the computer is used as a "tool'". How to evaluate and use this tool to assist English teaching is the "challenge" [17] the teachers should face. Referring to Levy [18], he states that, "evaluation in CALL should begin by carefully reviewing existing programs and learning environments, including those produced commercially, and reflecting upon their content, structure and design". An ethnographic study by Warschauer [19] shows reasons why on-line learning can motivate the learners. This study provides the basic principles for teachers to be assisted by computers. Furthermore, the teachers can not only adapt and adopt the materials from the Internet through computers but also make courseware by using programs like PowerPoint and Flash. Some kinds of courseware can be made very lively with both audios and videos together to present the text. Meanwhile, most of the materials used in the courseware are downloaded from the Internet. Nevertheless, since "the use of CAL can be seen to affect the teaching-learning situation in a variety of ways" [20], it is far from enough for teachers to make full use of computers. 


\section{Other aspects}

There are different ways of computer-mediated communicating via Internet. Email and MOOs are popular ones that are related to language teaching and learning.

The result of the research by Poulson[21] indicates that out of 30,321 written documents by business people, $98 \%$ of them are email. This gives an indication of focusing on what to teach, with an emphasis on writing skills. Email is not only the most important and popular activity on the Internet, but also an easy way to improve learning. Warschauer[22] gives three concrete reasons for using e-mail in the English classroom; that e-mail "provides students an excellent opportunity for real, natural communication; empowers students for independent learning" and "the use of e-mal enriches our experiences as teachers". That means it can create an authentic purpose for writing, and learners' autonomy is greatly enhanced. Moreover, practicing English through email benefits both teachers and students.

The advantage of the online environment like MOOs to learning a language is that "a learner can enter into an environment where a target language is being spoken and be forced to react to others' words and actions" [23]. Comparing with the asynchronous email, MOOs are synchronous and fluency is the main aim of practice.

In general, as Crystal [24] stresses, E-mails, chat groups, and the Web are all electronic interactions that are about "the real thing in the real world". As a result, they compensate the limitation of any course books and any supplementary materials by comprising authentic world with audio and visual resources. They provide more opportunity for Computer Assisted Language Learning and teaching and give powerful evidence on using computer as assistance in language classroom.

\section{CONCLUSION}

The above shows different ways in which the computer can assist in second language teaching and learning, but as Sokolik [25] argues, there are still many things the computer cannot accomplish like "machine translation; providing appropriate feedback to learners; voice recognition; grammar checking; and essay marking". On the other hand, nobody can deny the great help of the computers in modern language teaching and learning because "the aim of developing CALL is not to provide language learners with novelty, but to improve the quality of language teaching. The aim is not to show how ingenious we are in creating software but to use the computer to help us implement educational aims." [26] As we can see, the increasingly developed numbers of software will soon come into people's everyday life. The task for the educators about how to apply them into their class remains.

\section{REFERENCES}

[1] R. Ayres, "Learner Attitudes Towards the Use of CALL," Computer Assisted Language Learning 15/3, 2002, pp. 241.

[2] G. Davies, "CALL," LSTN Subject Centre for Languages, Linguistics and Ares http://www.lang.ltsn.ac.uk/resources/goodpractice.aspx?resourceid=6 1\#toc 13787. 2002.

[3] H. Jarvis, "Word-processing and writing skills: practical applications to language teaching text books," British Journal of Education Technology. 28/3, 1997a, pp.165.

[4] H. Jarvis, "Word-processing and writing skills: practical applications to language teaching text books," British Journal of Education Technology. 28/3, 1997a, pp.166.

[5] H. Jarvis, "Word-processing and writing skills: practical applications to language teaching text books," British Journal of Education Technology. 28/3, 1997a, pp.165-175.

[6] A. Piper, "Helping learners to write: a role for the word processor," ELT Journal. 41/2, 1987, pp.121.

[7] A. Piper, "Helping learners to write: a role for the word processor," ELT Journal. 41/2, 1987, pp.122-124.

[8] K. Beatty, "Teaching and Researching CALL," Longman, 2003, pp. 53.

[9] P. Brett, "An Intuitive, Theoretical and Empirical Perspective on the Effectiveness Question for Multimedia," In Cameron, K (1998)(ed) Multimedia CALL: Theory and Practice, Exeter: Elm Bank Publications, 1998, pp.81.

[10] S. Windeatt, D. Hardisty, \& D. Eastment, "The Internet," Oxford: OUP, 2000, pp.10.

[11] H. Jarvis, "Towards a classification making sense of the Internet in language teaching and teacher development," The Teacher Trainer 16/2, 2002, pp.16.

[12] H. Jarvis, "Using The World Wide Web for an 'authentic learning experience," Modern English Teacher 6/4, 1997b, pp.45.

[13] D. Teeler, with P. Gray, "How to use the Internet in ELT," Harlow: Longman, 2000, pp.36.

[14] S. Windeatt, D. Hardisty, \& D. Eastment, "The Internet," Oxford: OUP, 2000, pp.46.

[15] G. Dudney, "The Internet and the language classroom," Cambridge: CUP, 2000, pp.1.

[16] M. Carballo-Callero, "The EFL Teacher and the Introduction of Multimedia in the Classroom," Computer Assisted Language Learning 14/1, 2001, pp.4.

[17] I.M. Richmond, "Is Your CALL Connected?" In K. Camron(ed)(1999) CALL Media design and applications, Lisse: Sweets and Zeitlinger, 1999, pp. 312.

[18] M. Levy, "Design Processes in CALL: Integrating Theory, Research and Evaluation," In K. Cameron(ed)(1999) CALL Media design and applications Lisse: Sweets and Zeitlinger, 1999, pp. 98.

[19] M. Warschauer, "On-line learning in second language classrooms. An ethnographic study," In M. Warchauer\& R. Kern (eds.)(2000) Network-based Language teaching: Concepts and Practice New York: CUP, 2000, pp. 56.

[20] J. Chatterton, "Evaluating CAL in the classroom," In I. Reid \& J. Rushton(eds)(1985) Teachers, Computers and the Classroom Manchester University Press, 1985, pp.92.

[21] C. Poulson, "Are Business English course books on the write track?" 2005, unpublished.

[22] M. Warschauer, "E-Mail for English Teaching," Alexandria, Va.: TESOL, c, 1995, pp. 2.

[23] K. Beatty, “Teaching and Researching CALL," Longman, 2003, pp. 66.

[24] D. Crystal, "Language and Internet," Cambridge: CUP, 2001,pp. 171.

[25] M. Sokolik, "Computers in Language Teaching," In M. CelceMurcia (ed)(2001) Teaching English as a Second or Foreign Language ( $3^{\text {rd }}$ ed) Heinle \& Heinle, 2001, pp. 478-481.

[26] K. Cameron, "Computer Assisted Language Learning," Oxford: Intellect, 1989, pp. ix. 